\title{
ESTUDOS DAS MANIFESTAÇÕES PATOLÓGICAS EM IGREJA HISTÓRICA DO MUNICÍPIO DE LIMEIRA-SP
}

\author{
DE FREITAS, RAFAELA AMARAL \\ Graduanda em Engenharia Civil \\ Faculdades Integradas Einstein de Limeira \\ São Paulo; Brasil. \\ rafaamafreitas@gmail.com
}

\author{
GARCIA, LUCAS ALEXSANDRO \\ Graduando em Engenharia Civil \\ Faculdades Integradas Einstein de Limeira \\ São Paulo; Brasil. \\ lucasagarcia98@gmail.com
}

\author{
DO NASCIMENTO, TAYLA LUANA DIAS \\ Graduanda em Engenharia Civil \\ Faculdades Integradas Einstein de Limeira \\ São Paulo; Brasil. \\ tayla12luana@gmail.com
}

\author{
DA SILVA, FABIANA MARIA \\ Professora Doutora \\ Faculdades Integradas Einstein de Limeira \\ São Paulo; Brasil. \\ faby_febs@yahoo.com.br
}

\section{RESUMO}

O estudo das patologias das construções, bem como as medidas de intervenção e recuperação são assuntos de extrema importância para que as edificações possam garantir o seu desempenho por longo tempo, pois devido aos efeitos ambientais, toda construção sofre uma decadência progressiva do seu desempenho ao longo do tempo. Dentro deste contexto, este trabalho visa identificar e caracterizar as diversas patologias existentes na Igreja de Nossa Senhora da Boa Morte e Assunção, templo particular pertencente à confraria de mesmo nome, na cidade de Limeira, interior de São Paulo, Brasil. A igreja é considerada o edifício mais antigo da cidade, cuja construção se iniciou em 1856 e foi concluída em 15 de agosto de 1867. Foi realizada a visita in loco no imóvel e constatado que a Igreja apresenta vários tipos de manifestações patológicas na área externa e interna e com necessidade de intervenções para garantir que este patrimônio permaneça fazendo parte da história da cidade de Limeira-SP. Palavras-chave: Patrimônio histórico, Patologia, Inspeção, Manutenção.

\section{ABSTRACT}

The study of the pathologies of the constructions, just as intervention and restoration are extremely important issues so that buildings can ensure their long-term performance, because due to the environmental effects every building undergoes a progressive decline in performance over time. Within this context, this work aims to identify and characterize the various pathologies existing in the Church of Nossa Senhora da Boa Morte e Assunção, private temple belonging to the confraternity of the same name, in the city of Limeira, interior of São Paulo. The church is considered the oldest building in the city, whose construction began in 1856 and was completed on August 15, 1867. Was made the visit on site in the property and it has been found that the Church has various types of pathologies in the outer and inner area and in need of interventions to ensure that this patrimony remains part of the history of the city of Limeira-SP. Keywords: Historical Patrimony, Pathology, Inspection, Maintenance.

\section{INTRODUÇÃO}

Na cidade de Limeira no interior do estado de São Paulo, Brasil, encontra-se a Igreja de Nossa Senhora da Boa Morte e Assunção. É um templo particular pertencente à confraria de mesmo nome fundada em 1856. A igreja é considerada o edifício mais antigo da cidade, cuja construção se iniciou em 1858 e foi inaugurada com grande festividade em 15 de agosto de 1867 (AUGUSTI, BOSCHIERO, RUY, 2005).

A igreja Boa Morte, como é conhecida na cidade, é de propriedade particular, foi construída pela Irmandade Nossa Senhora da Boa Morte e Assumpção, quando na época, eles queriam uma igreja à altura da elite cafeeira (ROSADA, 2010). 
De acordo com Mineo (2009) é uma edificação do estilo barroco, foi construída sob responsabilidade do Barão de Cascalho e o arquiteto Aurélio Civatti. Para a construção foi utilizada mão de obra escrava, as paredes laterais são de taipa de pilão e as torres laterais em tijolos de barro. A cobertura, o acabamento interno, imagens e sinos foram importados de Portugal.

A figura 1 mostra o projeto arquitetônico da Igreja de Nossa Senhora da Boa Morte e Assunção com as técnicas que foram utilizadas para elevação das paredes. De acordo com Rosada et al. (2013), as paredes de taipa dos fundos possuem $90 \mathrm{~cm}$ de espessura, as paredes de taipa nas laterais possuem 1,35 $\mathrm{m}$ de espessura, as paredes de tijolos da fachada possuem 1,75 $\mathrm{m}$ de espessura e as paredes de tijolos das torres possuem 2,30 $\mathrm{m}$ de espessura.

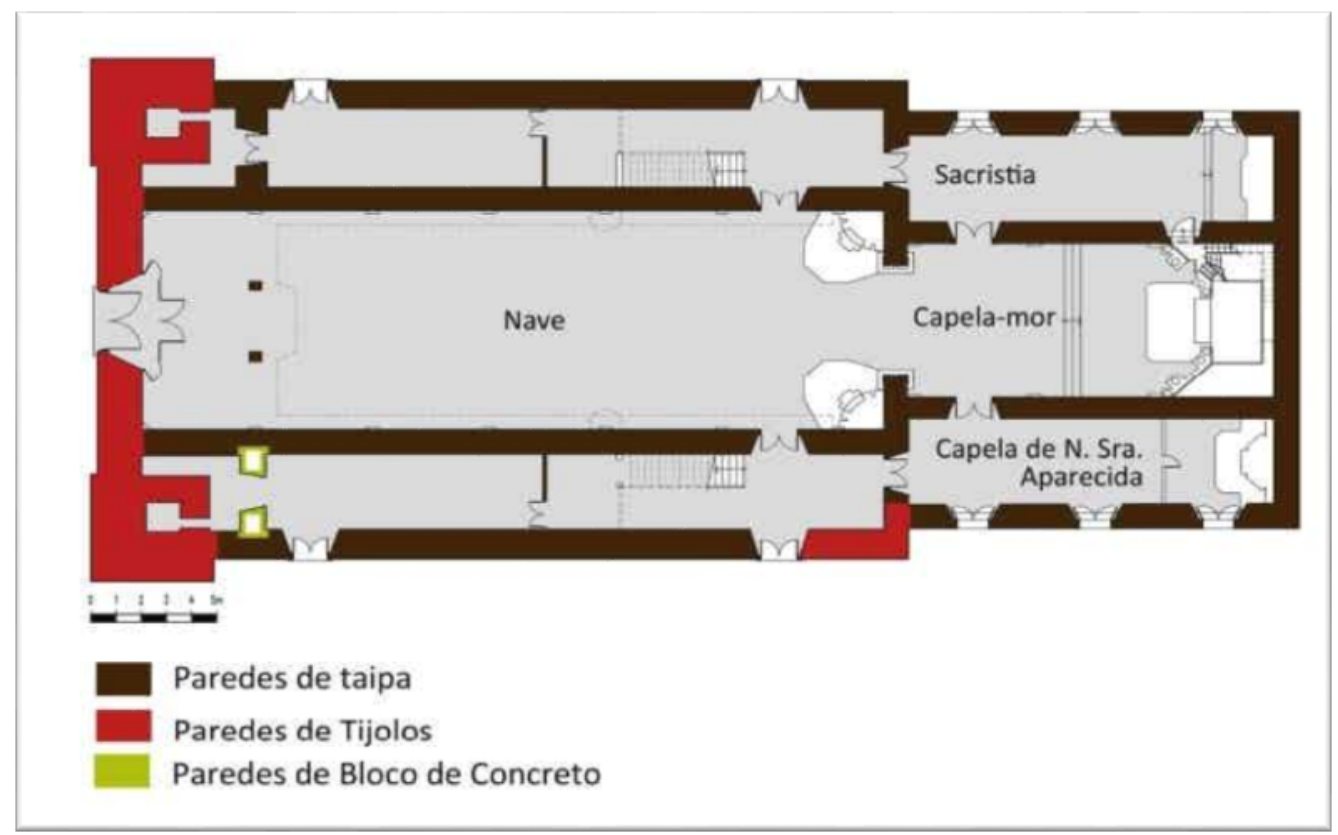

Figura 01: Projeto arquitetônico da Igreja de Nossa Senhora da Boa Morte e Assunção

Fonte: Rosada et al. (2013)

De acordo com Rosada (2010), a população na época pensava que a taipa duraria eternamente, no entanto, apenas doze anos após a inauguração, o edifício já começou a apresentar problemas: parte de sua fachada estava em mau estado e ameaçava desabar, apresentava problemas sérios de recalques na frente da igreja. Para tentar resolver o problema foi realizada uma intervenção com tijolos e pedras na fundação, mas isso não surtiu efeito e acabou agravando ainda mais a estabilidade da fachada, sendo necessária a contratação de uma comissão de técnicos especializados que constataram uma série de problemas na edificação.

De acordo com Pereira (2004), foi realizado um laudo técnico para o projeto de restauração na Igreja de Nossa Senhora da Boa Morte e Assunção e foram encontradas as seguintes patologias:

- Depressão nos alicerces com o deslocamento da frente e o risco da fachada desmoronar, provavelmente devido a falta de homogeneidade dos materiais e má execução da obra;

- Foram cavados os antigos alicerces, e substituído boa parte da terra por tijolos e pedra. A falta de amarração dos tijolos com a taipa contribuiu para o mal estado encontrado;

- A sobrecarga de peso nas abóbadas resultou no aparecimento de frestas e desnível no entablamento do assoalho do coro, nas escadas das torres e depressão dos alicerces;

Em entrevista realizada com o Secretário da Igreja Sr. Vardir Grego, foi relatado que a igreja nunca foi reformada por completo, porém, passou por várias reformas e reconstruções de trechos, modernizações e repinturas, que alteraram algumas de suas características originais, mas que, por outro lado, permitiu que o edifício se mantivesse íntegro até os dias atuais. 
Atualmente a igreja continua precisando de intervenções e reparos, portanto o objetivo deste trabalho foi identificar e classificar as manifestações patológicas visíveis presentes na edificação, analisar as possíveis causas e apontar as melhores soluções de reparo.

\section{MATERIAL E MÉTODOS}

Para a detecção das patologias a metodologia utilizada foi a realização de uma inspeção visual acompanhada por registros fotográficos seguindo especificações da norma de inspeção predial nacional do Instituto Brasileiro de Avaliações e Perícias de Engenharia (IBAPE) publicada em 2012. A norma define a inspeção predial como uma análise isolada ou combinada das condições técnicas, de uso e manutenção da edificação.

Foi realizado o levantamento das patologias existentes e apontadas as possíveis causas e soluções para o reparo. O secretário da paróquia Sr. Valdir Grego autorizou os registros fotográficos e relatou algumas manifestações patológicas e algumas curiosidades da época que também colaboraram para a realização deste trabalho.

\section{RESULTADOS}

$\mathrm{Na}$ parte externa da edificação foram identificadas as patologias apresentadas nas figuras 2, 3, 4, e 5 . E na tabela 1 estão relacionadas as manifestações patológicas, as possíveis causas e soluções.

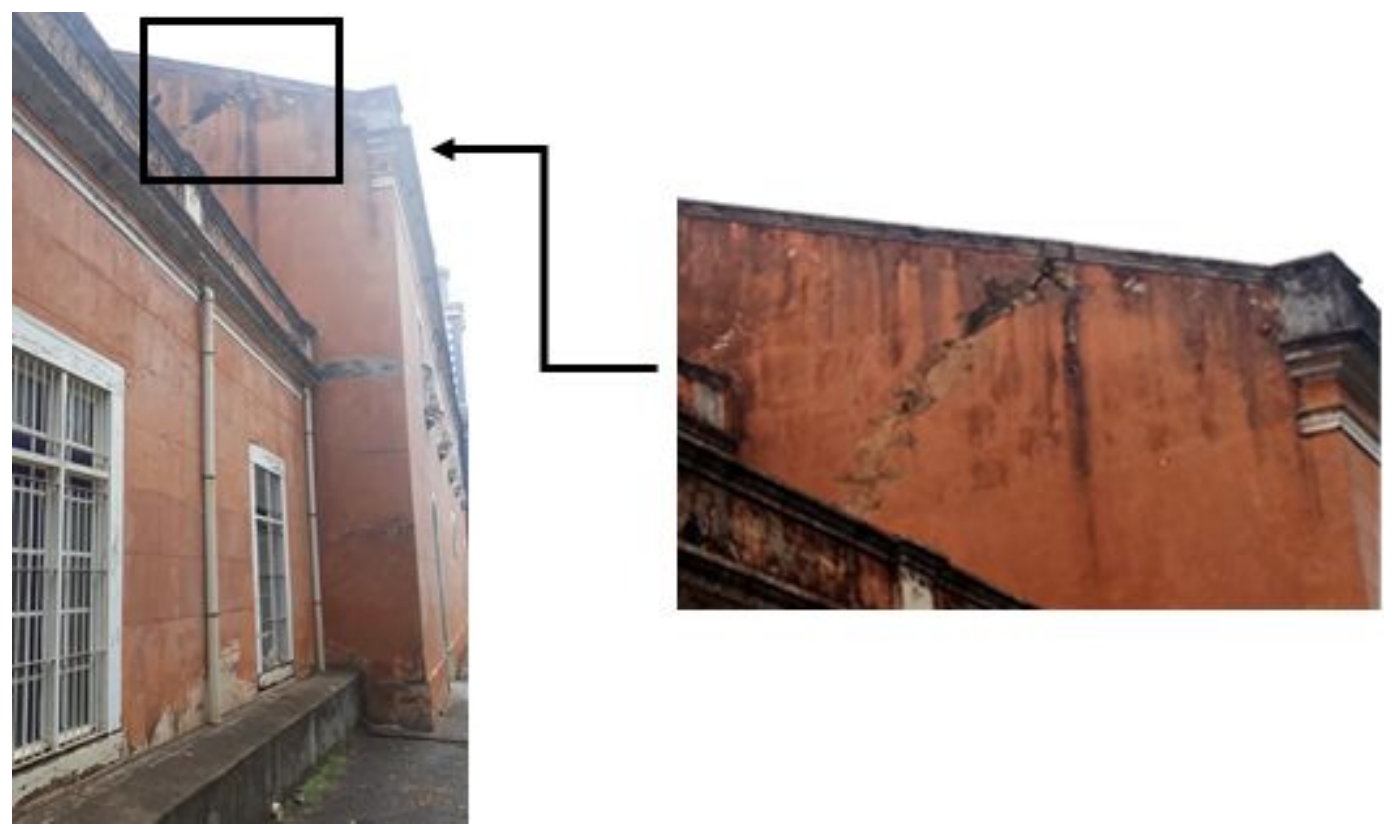

Figura 2 : Bolor, deterioração da pintura, infiltrações e fissuras 


\section{СВРAT 2020

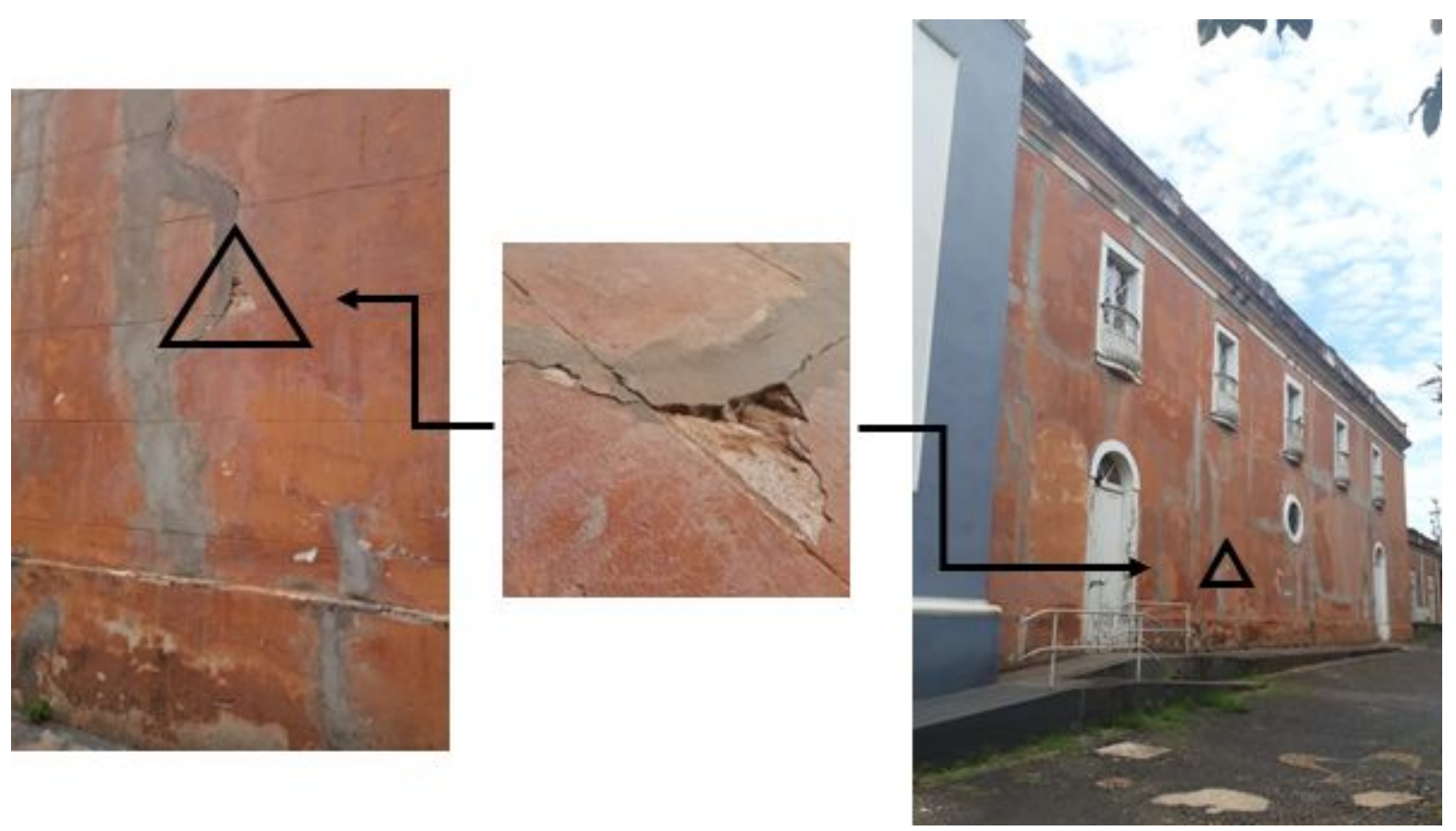

Figura 3: Erosão e trincas nas paredes

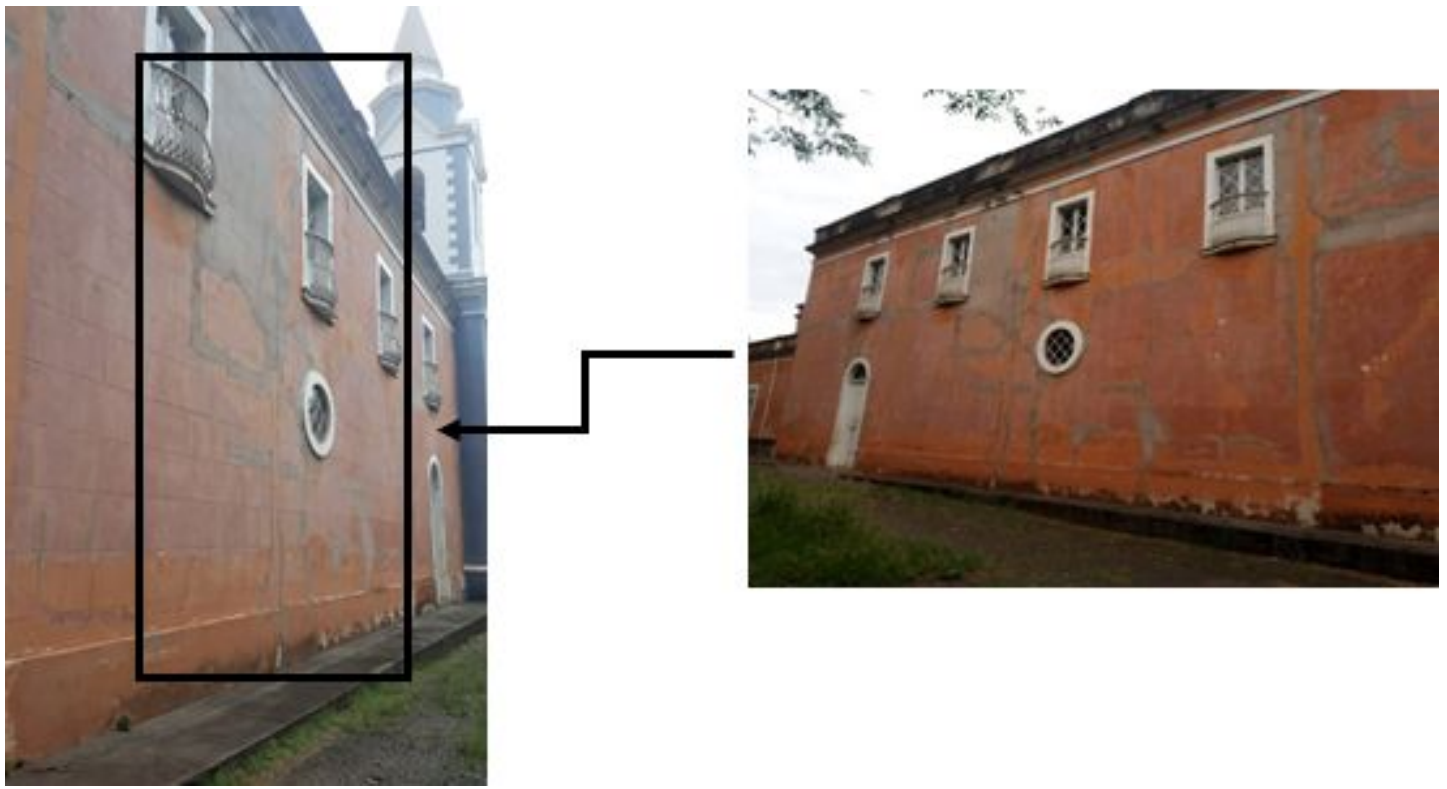

Figura 4: Fissuras de retração e eflorescências 


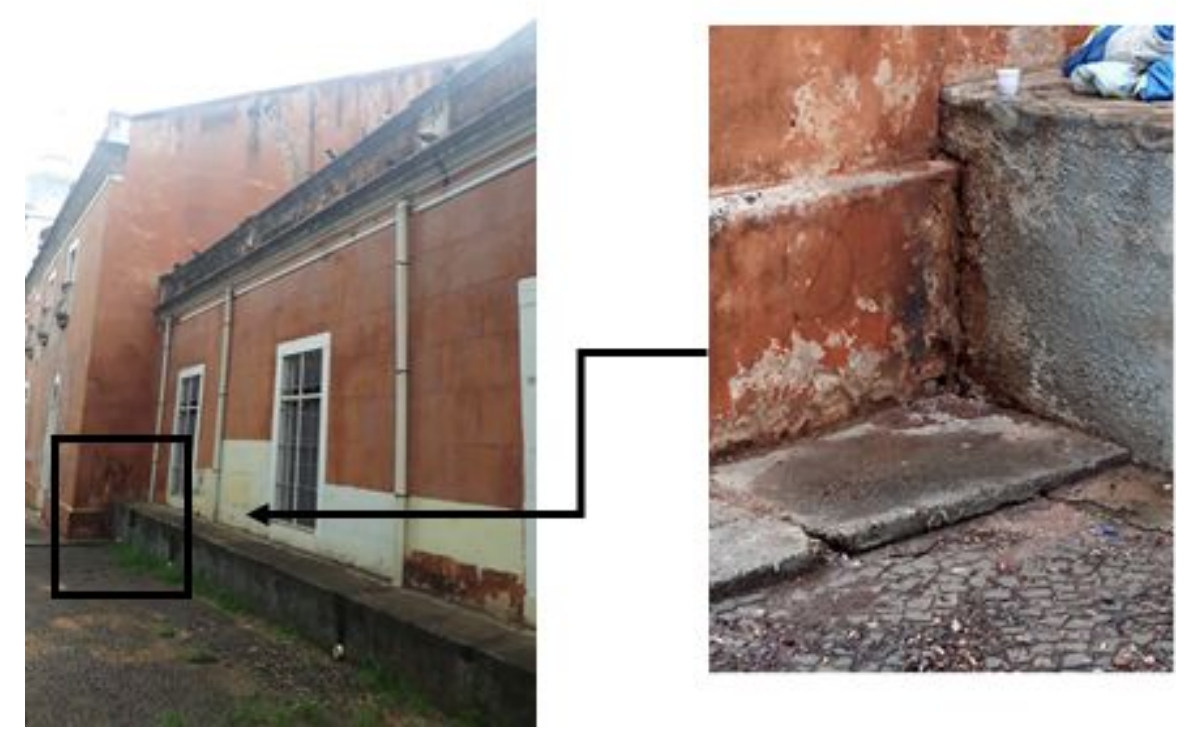

Figura 5: Deterioração da pintura com manchas, empolamento e infiltração

Tabela 1- Manifestações patológicas, causas e soluções (parte externa da edificação)

\begin{tabular}{c|c|c}
\hline Manifestações patológicas & Causa & Solução \\
\hline Trincas e fissuras & Exç̧as de tração, compressão \\
e recalque & $\begin{array}{c}\text { Argamassa com aditivos } \\
\text { poliméricos, nova } \\
\text { impermeabilização e pintura }\end{array}$ \\
\hline Bolor & Umidade e sais cristalizados & $\begin{array}{c}\text { Lavagem para remoça do mofo e } \\
\text { bolor e refazer a } \\
\text { pintura com produto antimofo }\end{array}$ \\
\hline Eflorescência & $\begin{array}{c}\text { Lavagem para remoção dos sais } \\
\text { cristalizados na } \\
\text { superfície, Impermeabilização com } \\
\text { produto } \\
\text { hidrofugante }\end{array}$ \\
\hline Pintura danificada & Empolamento da pintura e umidade & $\begin{array}{c}\text { Remoção da camada de reboco, } \\
\text { refazer reboco impermeabilização e } \\
\text { revestimento }\end{array}$ \\
\hline
\end{tabular}

As figuras $6,7,8,9,10,11$ apresentam os registros fotográficos das manifestações patológicas identificadas da parte interna da edificação. A figura 12 mostra o mapeamento das manifestações patológicas na planta baixa da edificação. Na tabela 2 estão relacionadas as manifestações patológicas, as possíveis causas e soluções. 

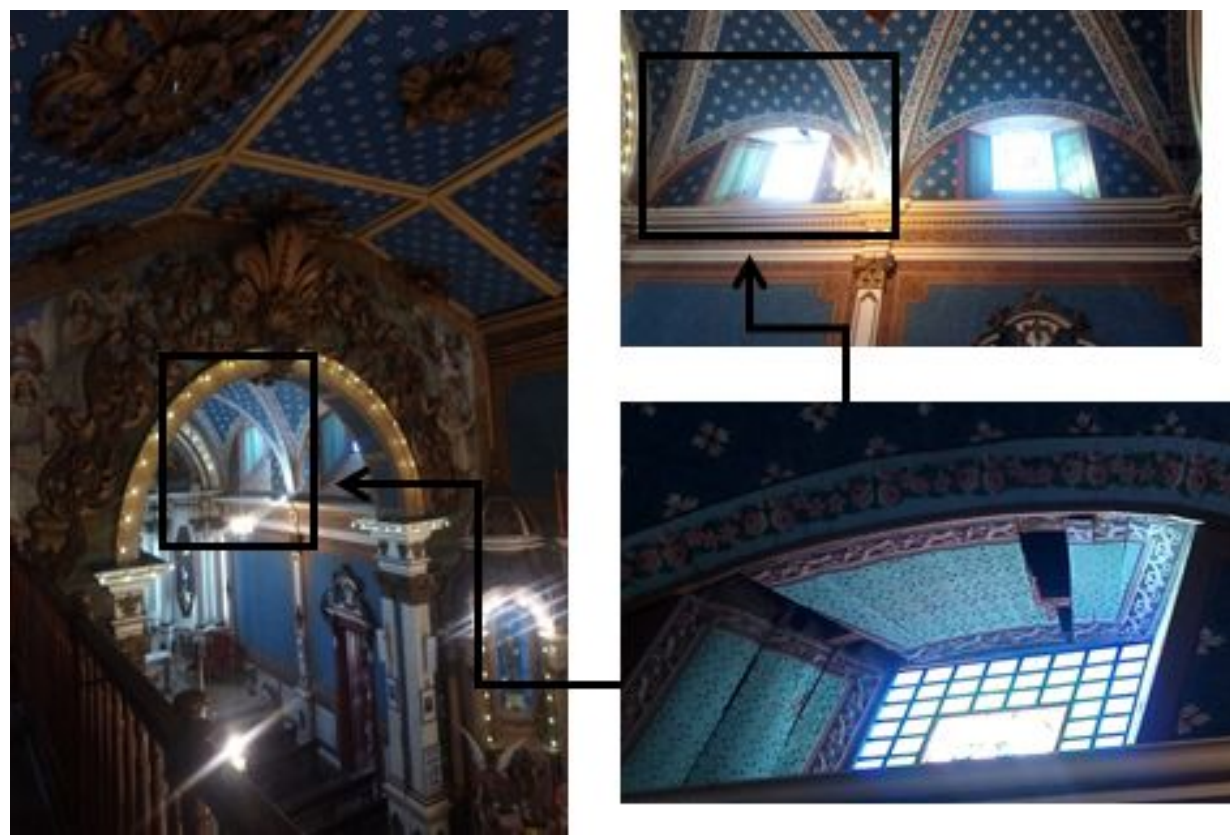

Figura 6: Lacunas e desprendimento da madeira.
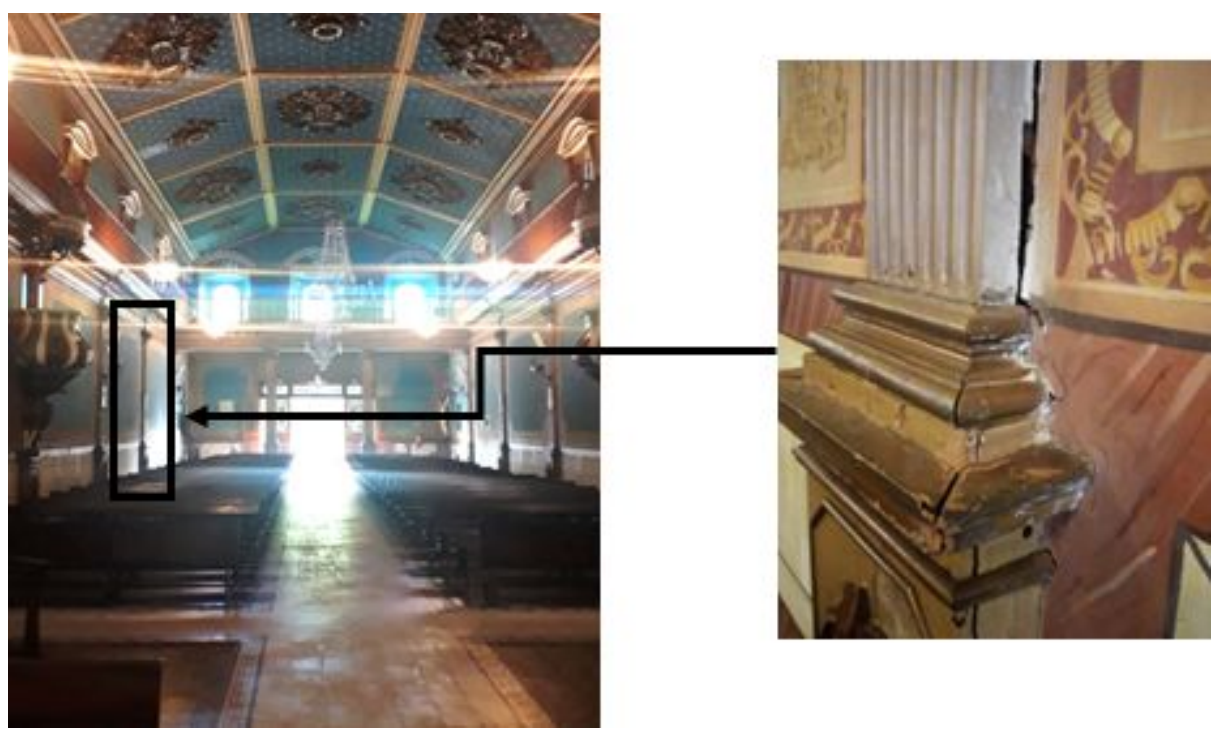

Figura 7: Fissuras nos pilares de madeira 

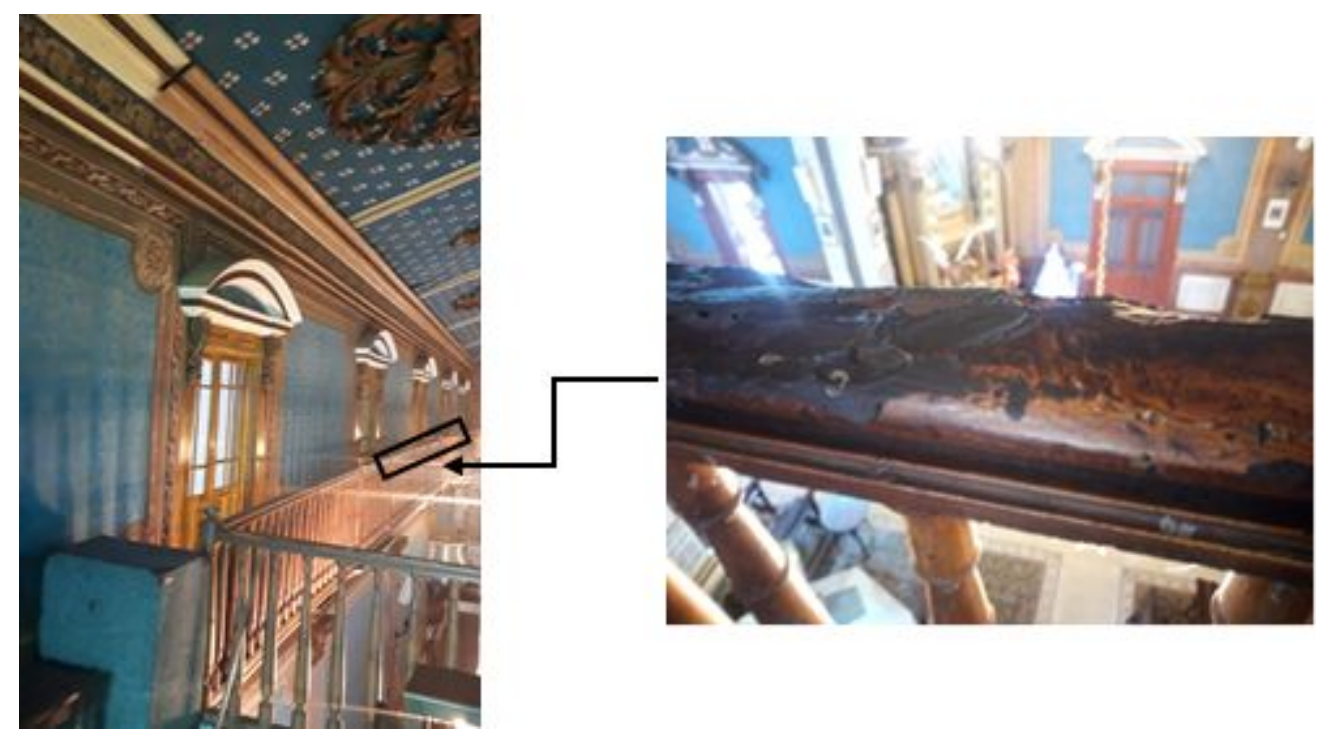

Figura 8: Corrimão original da época desgastado pela ação de insetos xilófagos

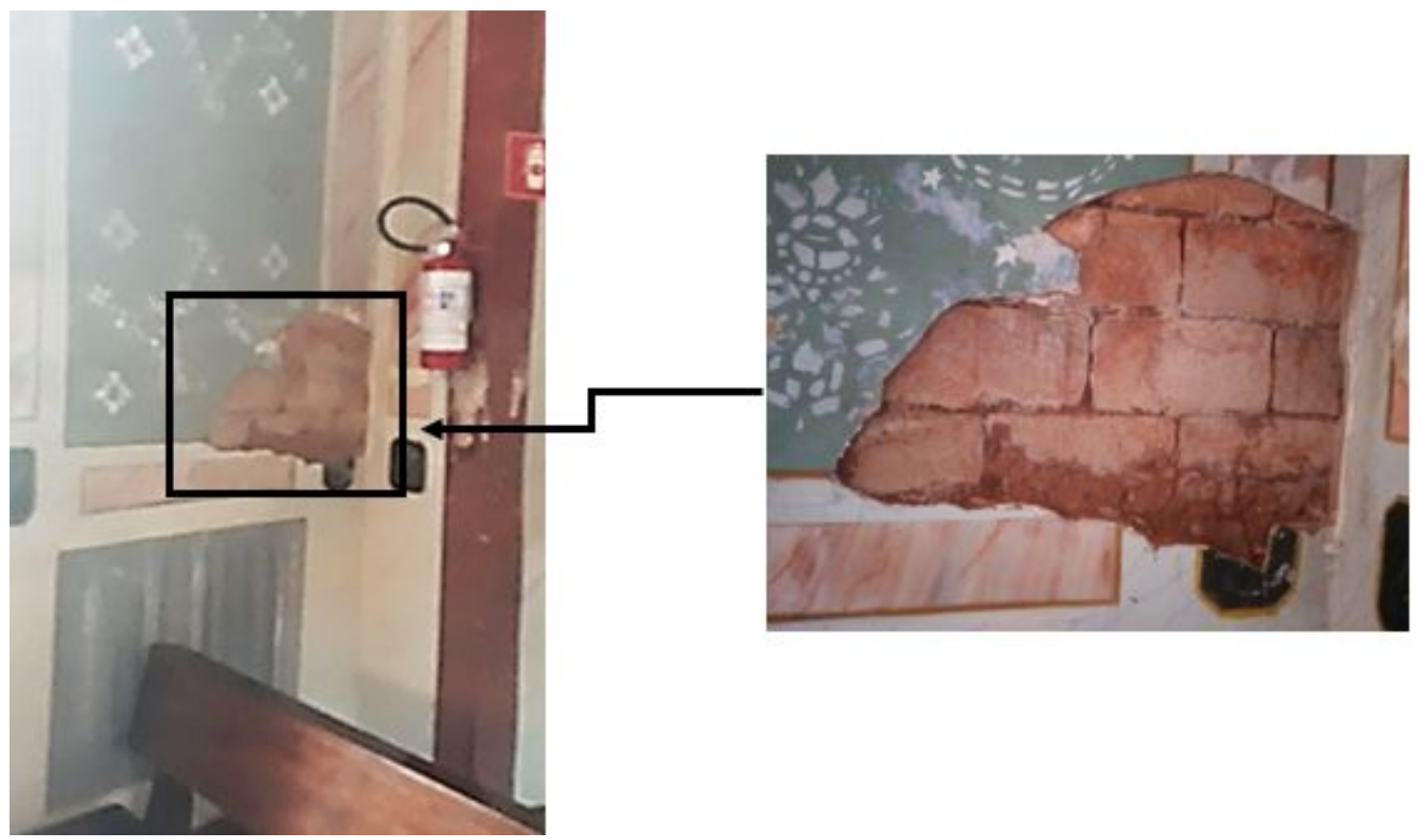

Figura 9: Desprendimento da camada de revestimento 


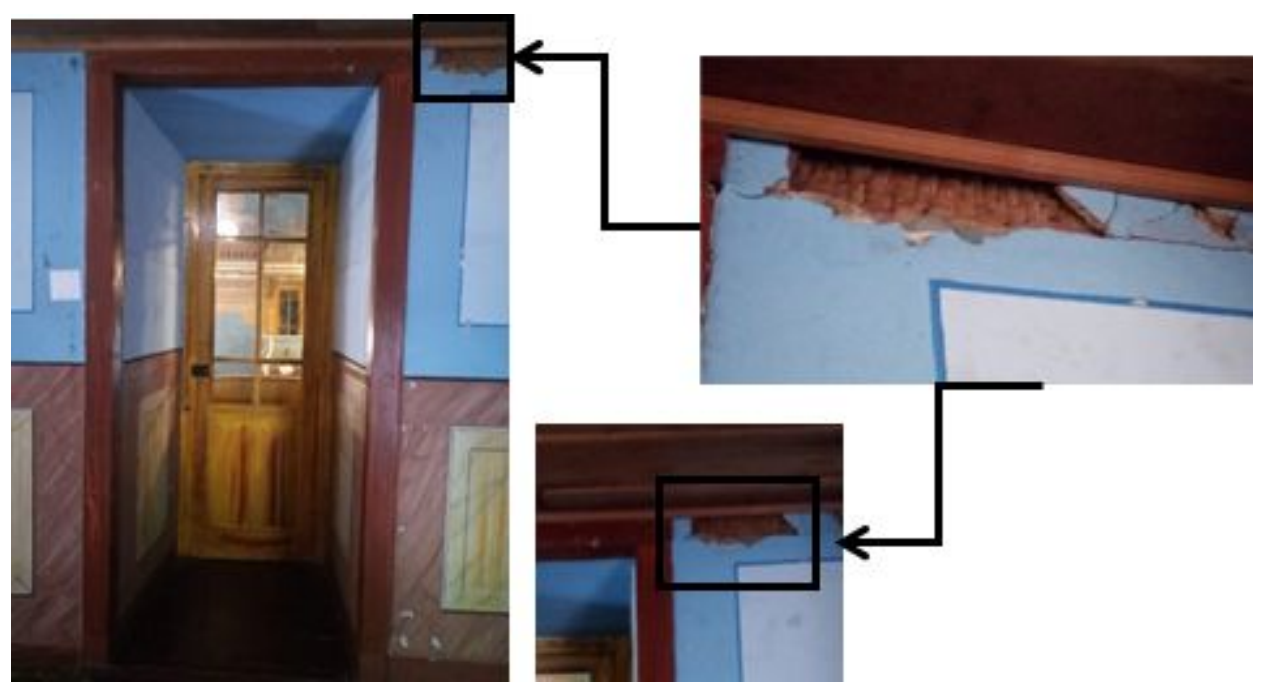

Figura 10: Erosão na parte superior da parede e desprendimento do revestimento

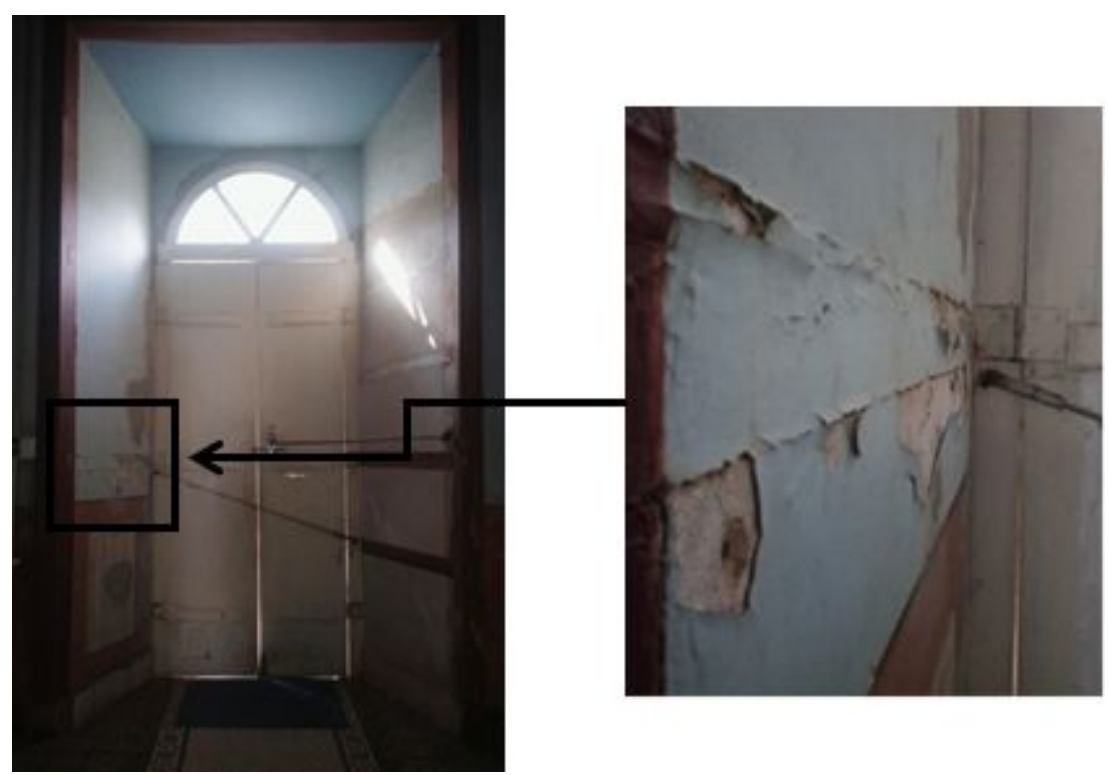

Figura 11: Pintura danificada com o aparecimento de bolhas de ar devido a infiltrações 


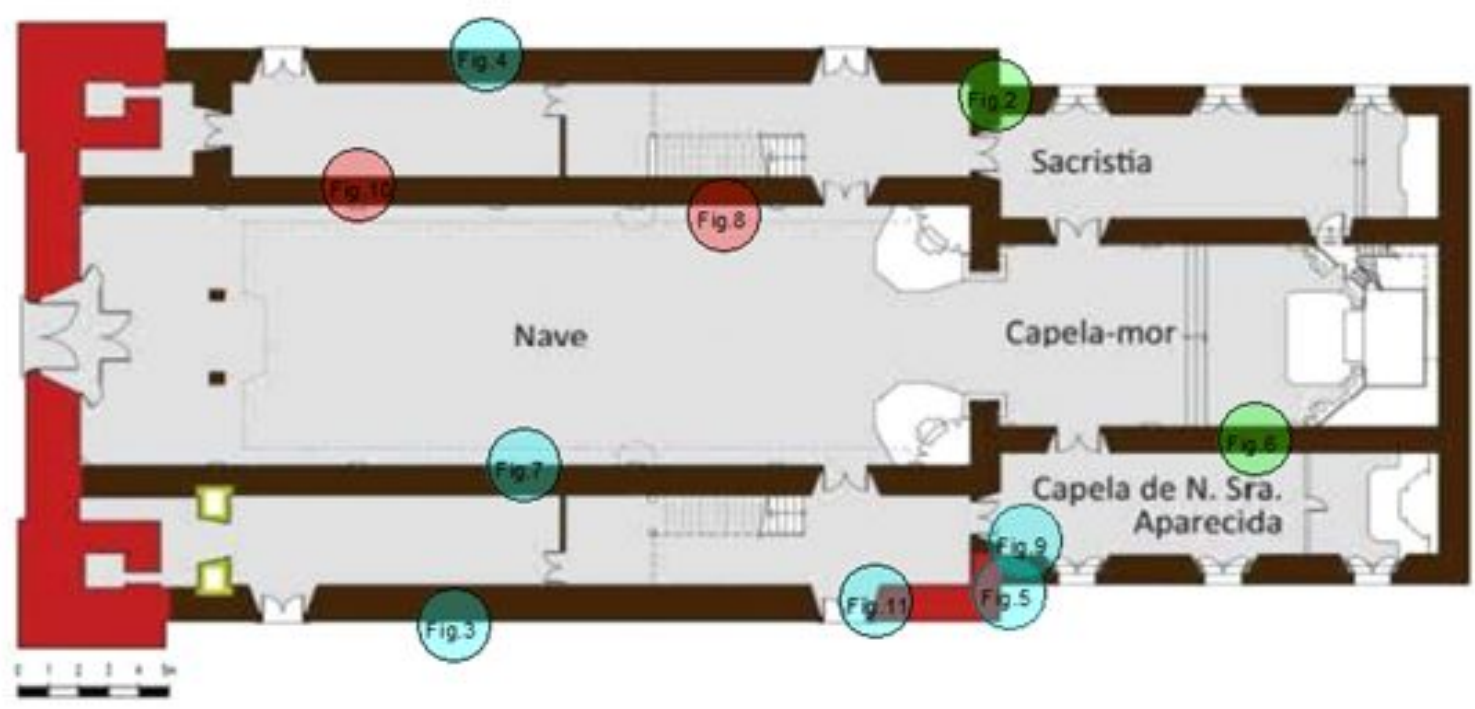

Patologias no Térreo

Patologias no Pavimento Superior

Patologias na Cobertura

Figura 12: Localização das Manifestações patológicas na Igreja de Nossa Senhora da Boa Morte e Assunção

Tabela 2 - Manifestações patológicas, causas e soluções (Parte interna da edificação)

\begin{tabular}{c|c|c}
\hline Manifestações patológicas & Causa & Solução \\
\hline $\begin{array}{c}\text { Deterioração e desprendimento da } \\
\text { madeira }\end{array}$ & $\begin{array}{c}\text { Dilatação natural, presença de } \\
\text { insetos e infiltrações de águas } \\
\text { pluviais }\end{array}$ & $\begin{array}{c}\text { Tratar quimicamente as superfícies } \\
\text { contra infestações de insetos } \\
\text { xilófagos (cupins), consertar o } \\
\text { telhado e substituir parte da } \\
\text { estrutura por madeira nova tratada }\end{array}$ \\
\hline Fissuras & Forças de tração e compressão & Umidade \\
\hline Trincasina ou adesivos epóxi
\end{tabular}

\section{DISCUSSÃO DOS RESULTADOS}

Observa-se que a umidade tem sido uma das principais causas das patologias existentes, prejudicando o desempenho da edificação e principalmente a estética. De acordo com Bertoline (2010), a umidade pode ser causada durante a execução da obra pelos materiais utilizados, por águas da chuva, por capilaridade, por condensação, absorção dos materiais ou vazamentos de tubulações hidráulicas. 
O uso da madeira é presente no interior da edificação, no entanto, a falta de manutenção e as condições de umidade tem propiciado um ambiente para a infestação de insetos e proliferação de fungos degradadores. Segundo Bertoline (2010) os fungos se desenvolvem em ambientes com umidade acima de $20 \%$, com temperatura ideal entre $25^{\circ} \mathrm{C}$ e $30^{\circ} \mathrm{C}$, na presença de oxigênio, pois não sobrevivem submersos, com pouca luz solar e com pH levemente ácido (entre 4,5 e 5,5, pois não toleram ambiente alcalino ( $\mathrm{pH}$ acima de 7).

Segundo informações do Secretário Sr. Valdir Grego, a Igreja tem realizado um tratamento com produtos químicos nas superfícies das paredes contra infestações de insetos xilófagos (descupinização) ao menos uma vez por ano, no entanto, nota-se que a falta de manutenção preventiva e corretiva tem agravado as condições patológicas da edificação e que há necessidade de intervenção e reparos.

\section{CONCLUSÃO}

Ter acesso direto aos métodos construtivos da época e conhecimento sobre as soluções de restauro é uma forma de garantir o desempenho das edificações por longo tempo.

As manifestações patológicas que são comumente encontradas nas edificações podem ser evitadas com a escolha dos materiais adequados, correta execução, bom dimensionamento e manutenção, a fim de garantir o conforto, qualidade e segurança aos usuários.

Por meio da inspeção visual das manifestações patológicas da Igreja de Nossa Senhora da Boa Morte e Assunção, verificou-se que a falta de manutenção periódica tem sido um agravante para o desempenho quanto ao conforto e segurança da edificação.

Existe um projeto para o restauro da igreja com apoio técnico de uma equipe de Campinas-SP. A equipe realizou uma inspeção técnica no local por meios de ensaios não destrutivos para a verificação da estabilidade estrutural da edificação e a obra poderá ser iniciada em 2020.

Espera-se que a igreja seja restaurada por completa e que sejam tomadas as devidas medidas de prevenção e manutenção da edificação, para que ela continue compondo o patrimônio histórico da cidade de Limeira por muitos anos.

\section{AGRADECIMENTOS}

Os autores agradecem a confraria Nossa Senhora da Boa Morte e Assunção, por acesso à Igreja para a elaboração do parecer. Em especial ao Secretário da Igreja Valdir Grego, que disponibilizou seu tempo para nos apresentar a história e as condições atuais da igreja.

\section{REFERÊNCIAS}

Augusti, V.M., BOSChIERO, D., RUY, D.P. A festa e a Igreja Nossa Senhora da Boa Morte Assunção: patrimônios a serem reservados. Caderno virtual de turismo, v. 5, nº 2, 2005.

BERTOLINE, Luca. Materiais de construção: patologia, reabilitação, prevenção, São Paulo, Oficina de textos, 2010 .

CARITÀ, W. J. Breve história da Confraria de Nossa Senhora da Boa Morte e Assumpção, Sociedade Pró-Memória de Limeira, 1998.

IBAPE - Instituto Brasileiro de Avaliações e Perícias de Engenharia, Norma de Inspeção Predial Nacional, São Paulo-SP, 2012.

MINEO, M.M.P. O espaço urbano e suas temporalidades: diagnóstico e proposta de intervenção para o patrimônio histórico do Centro de Limeira-SP. Dissertação de Mestrado, Universidade Estadual Paulista - Rio Claro-SP, 2009. 
PEREIRA, J. B. Memorial de Restauro: Igreja de Nossa Senhora da Boa Morte e Assumpção. Monografia (Especialização). Faculdade de Arquitetura e Urbanismo Católica de Campinas, 2004.

PEREIRA, Juliana Binotti. Memorial de Restauro: Igreja de Nossa Senhora da Boa Morte e Assumpção. Monografia (Especialização). Faculdade de Arquitetura e Urbanismo. Pontifícia Universidade Católica de Campinas. Campinas, 2004.

PISANI, M. A. J. Restauração das paredes de Taipas Paulistas In: II Congresso Internacional na recuperação, manutenção e restauração de edifícios. Universidade Presbiteriana Mackenzie e Universidade Federal do Rio de Janeiro, maio de 2006.

ROSADA, M. Sob o signo da Cruz :Igreja estado e secularização (Campinas e Limeira 1774 -1939) Dissertação de Mestrado. Faculdade de Arquitetura e Urbanismo, Universidade Estadual de São Paulo, 2010.

ROSADA, M., CASTro, M.A.P., BORTOlUCCI, S. A igreja da Boa Morte de Limeira: Uma Amálgama de conhecimentos Forâneos. In IX EHA - ENCONTRO DE HISTÓRIA DA ARTE - UNICAMP, 2013. 